\title{
Erratum to: Axionic charged black branes with arbitrary scalar nonminimal coupling
}

\author{
Adolfo Cisterna $^{1, \mathrm{a}}$, Luis Guajardo ${ }^{2, \mathrm{~b}}$, Mokhtar Hassaine ${ }^{2, \mathrm{c}}$ \\ ${ }^{1}$ Universidad Central de Chile, Vicerrectoría Académica, Tosca 1783, Santiago, Chile \\ ${ }^{2}$ Instituto de Matemática y Física, Universidad de Talca, Casilla 747, Talca, Chile
}

Published online: 23 August 2019

(C) The Author(s) 2019

Erratum to: Eur. Phys. J. C (2019) 79:418 https://doi.org/10.1140/epjc/s10052-019-6922-1

The original version of this article unfortunately contains a mistake: the affiliation of the first author Adolfo Cisterna is incorrectly given as "Central de Chile, Vicerrectoria académica, Toesca 1783, Santiago, Chile". The correct affiliation of the first author Adolfo Cisterna is "Universidad Central de Chile, Vicerrectoría Académica, Tosca 1783, Santiago, Chile".

Open Access This article is distributed under the terms of the Creative Commons Attribution 4.0 International License (http://creativecomm ons.org/licenses/by/4.0/), which permits unrestricted use, distribution, and reproduction in any medium, provided you give appropriate credit to the original author(s) and the source, provide a link to the Creative Commons license, and indicate if changes were made.

Funded by $\mathrm{SCOAP}^{3}$.

The original article can be found online at https://doi.org/10.1140/ epjc/s10052-019-6922-1.

\footnotetext{
a e-mail: adolfo.cisterna@ucentral.cl

b e-mail: luis.guajardo.r@gmail.com

c e-mail: hassaine@inst.mat.utalca.cl
} 